\title{
Photophysical Properties and Quantum Chemical Studies of Poly(2,7-9,9'-dihexylfluorene-dyil)
}

\author{
Hueder P. M. Oliveira, ${ }^{a}$ Tatiana D. Martins, ${ }^{a}$ Kathia M. Honório, ${ }^{b}$ Paula C. Rodrigues, ${ }^{b}$ \\ Leni Akcelrud, ${ }^{b}$ Albérico B. F. Silva ${ }^{c}$ and Teresa D. Z. Atvars $*, a$ \\ anstituto de Química, Universidade Estadual de Campinas, CP 6154, 13084-971 Campinas-SP, Brazil \\ ${ }^{b}$ Departamento de Química, Universidade Federal do Paraná, CP 19081, 81531-990 Curitiba-PR, Brazil \\ 'Instituto de Química de São Carlos, Universidade de São Paulo, CP 780, 13560-970 São Carlos-SP, Brazil
}

\begin{abstract}
Este trabalho descreve as propriedades fotofísicas (espectros de excitação e de fluorescência, rendimento quântico e tempo de meia-vida de fluorescência) do poli(2,7-9,9'diexil-fluoreno-diil) em soluções diluídas, de quatro solventes (tolueno, tetraidrofurano, clorofórmio e acetato de etila) e no estado sólido. Os espectros de fotoluminescência são característicos da conformação desordenada da cadeia principal, denominada forma $\alpha$. Espectros eletrônicos de absorção foram simulados para oligômeros de 1 a 11 meros, indicando que o comprimento crítico de conjugação está entre 6 e 7 meros. Os valores teóricos do momento de dipolo mostraram que a conformação helicoidal formada se repete a cada 8 unidades por volta. Mostra-se ainda que no estado sólido ocorrem processos de transferência de energia que levam a uma diminuição do tempo de meia-vida de fluorescência. Com base nos espectros obtidos, pode-se concluir que a fotoluminescência e a eletroluminescência descrita na literatura são provenientes das mesmas unidades emissoras.
\end{abstract}

This work reports the photophysical properties (excitation and fluorescence spectra, fluorescence quantum yield, fluorescence lifetimes) of the poly(2,7-9,9'-dihexylfluorene-dyil) in dilute solutions of four solvents (toluene, tetrahydrofuran, chloroform and ethyl acetate) as well as the properties in solid state. Photoluminescence showed spectra characteristic of disordered $\alpha$-backbone chain conformation. Simulation of the electronic absorption spectra of oligomers containing 1 to 11 mers showed that the critical conjugation length is between 6 and 7 mers. We also estimated the theoretical dipole moments which indicated that a coil conformation is formed with 8 repeating units per turn. We also showed that some energy transfer process appears in solid state which decreases the emission lifetime. Furthermore, based on luminescent response of the systems herein studied and electroluminescent behavior reported on literature, both photo and electroluminescence emissions arise from the same emissive units.

Keywords: polyfluorene, photophysical properties, quantum mechanical calculation, photoluminescence

\section{Introduction}

Polyfluorene and derivates form a class of conjugated polymers whose photoluminescence emission is strongly dependent on their chemical structure ranging from the violet to red. ${ }^{1-8}$ Several of them are also electroluminescent materials. ${ }^{1,4-9}$ The backbone of fluorene-based polymers contains a rigidly planar biphenyl structure which can be functionalized in the C-9 position to enhance the polymer solubility. Nevertheless, this substitution at C-9 induces

\footnotetext{
*e-mail: tatvars@iqm.unicamp.br
}

minor steric effects in the adjacent aromatic rings, ${ }^{10}$ leading, in general, to small geometrical disturbance. It is also well known that some polyfluorenes in solid state may form liquid-crystalline phases, with high ordered crystalline phases with thermotropic phase transition from 100 to $170{ }^{\circ} \mathrm{C} .{ }^{11}$ Moreover, the polymer chain may be organized in the solid state undergoing phase structure with different spectral properties: more ordered $\alpha$-phase or more disordered $\beta$-phase. ${ }^{12-15}$ Solvent properties and processing conditions play important role on the crystalline phase distribution and polymer chain conformation. ${ }^{9,13,16-22}$ 
The spectral range of emission of conjugated polymers depends on several intrinsic or extrinsic parameters. , $13,16-22^{-1}$ Among the intrinsic parameter the energy gap between the electronic bands is important and is associated with the critical conjugation length. ${ }^{19,18}$ Evidences of the dependence of conjugation length and band position can be obtained either experimentally or using quantum mechanical theoretical techniques. For example, we observed that for conjugated-nonconjugated alternated copolymers, the emission band is defined by the conjugated group and small spectral shifts were observed when compared with the isolated lumophores. ${ }^{1-3,9,18,23}$ The critical conjugation length may be determined by theoretical quantum mechanical calculations based on the red-shift of the energy gap between the highest occupied molecular orbital (HOMO) and the lowest unoccupied molecular orbital (LUMO) for larger oligomers. In general it has been observed that the critical conjugation length involves between 7 and 12 mers, depending on the polymer. ${ }^{24}$

There are several theoretical approaches for quantum mechanical calculations..$^{25,26}$ The criterion for choosing a methodology is the compromise between the accuracy of the calculated data and the computational effort. In the present work, the theoretical spectra were obtained with the semi-empirical method INDO ${ }^{25,27}$ as implemented in the molecular package Cerius, ${ }^{2}$ using gaussian lineshapes with full-width at half maximum. ${ }^{28}$ Several reports indicated that this is a convenient approach since this methodology combines good data quality with reasonable computational effort. ${ }^{3,29}$ The theoretically simulated spectra of some fluorene oligomers were compared with the experimental UV-Vis spectra of the poly(2,7-9,9'-dihexylfluorenedyil) (PHF, Scheme 1) in dilute solutions. The number of repeating units in the oligomers varied from $n=1$ to $n=8$ and for each one of these we obtained the optimized geometry, the dipole moment, the electronic energy levels and the correspondent simulated electronic absorption spectra.

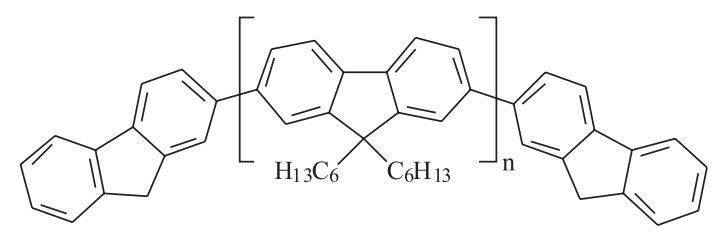

Scheme 1. Chemical structure of poly(2,7-9,9'-dihexylfluorene-dyil) (PHF).

In general, electronic absorption and emission spectra in solid state are different of those in dilute solutions. ${ }^{2-4,22,23}$ The reason for such differences is the occurrence of aggregation process that influences not only the spectral profile but also the emission intensity. In particular for conjugated polymers which undergo photo and electroluminescence, ${ }^{1-9}$ it has been observed in several cases that both emissions are very similar, and thus the knowledge of the solid state emission is important. Here we compare the spectral profile of PHF in solid state and in dilute solutions in an attempt to identify the lumophores responsible by the emission. Electronic absorption and fluorescence spectra of dilute PHF solutions in toluene, tetrahydrofuran, chloroform and ethyl acetate were recorded and analyzed. These solvents have similar Hildebrand solubility parameters, ${ }^{30}$ although their components dispersive and dipolar are different, playing different role on the solvation ability of polyfluorenes. ${ }^{31}$ Also, simulated theoretically the absorption spectra of several oligomers to estimate the value of the critical length of the conjugated segment.

\section{Experimental}

\section{Materials}

Toluene, tetrahydrofuran, chloroform and ethyl acetate, HPLC grade, from Sigma-Aldrich were used. Poly(2,7-9,9'dihexylfluorene-dyil) (PHF) was synthesized by according the protocol described elsewhere. ${ }^{1,32}$ Molecular weight was determined as $\overline{\mathrm{M}} \mathrm{n}=8500 \mathrm{~g} \mathrm{~mol}^{-1}$ and polydispersity of 1.4 by gel permeation chromatography.

Thin films of the polymer were prepared by spincoating on a glass substrate. Droplets of a PHF solution in chloroform $\left(0.09 \mathrm{~g} \mathrm{~mL}^{-1}\right)$ sprinkled on the glass plate rotating with 1500 RPM in a Specialty Coating Systems Inc., model 6780D 8" Desk-Top Precision. After deposition the film was dried at $50{ }^{\circ} \mathrm{C}$ for $40 \mathrm{~min}$ in an oven under dynamic vacuum. Film thickness was determined using an Alfa Step 500 profilometer, as $70 \mathrm{~nm}$.

\section{Methods}

The PHF samples were characterized by ${ }^{1} \mathrm{H}$ NMR in $\mathrm{CDCl}_{3}$ at $400 \mathrm{MHz}$ and ${ }^{13} \mathrm{C}$ in $\mathrm{CDCl}_{3}$ at $100 \mathrm{MHz}$, by elementary analysis and by differential scanning calorimetry with a DuPont DSC form v2.2A 90, calibrated with indium as standard. All experimental details and data were reported in reference 32 .

Electronic absorption spectra of the PHF solutions were recorded with a Varian (Cary 5G) UV-Vis spectrophotometer using a $1 \mathrm{~cm}$ square quartz cuvette and each solvent was previously used as blank for spectra recording. Steady-state fluorescence spectra of PHF solutions (concentration = $1.2 \times 10^{-5} \mathrm{~mol} \mathrm{~L}^{-1}$ ) were recorded using an ISS-PC1 spectrofluorimeter operating with a $300 \mathrm{~W}$ Xe arc lamp. 
Emission spectra were recorded from $370 \mathrm{~nm}$ to $700 \mathrm{~nm}$, with excitation at $\lambda_{\text {exc }}=310 \mathrm{~nm}$. The quantum yield of the copolymer emission in solution was also determined by the steady-state fluorescence using quinine sulfate as standard. ${ }^{33}$

Fluorescence lifetimes were obtained using timecorrelated single photon counting method in a FL 900 spectrofluorimeter (Edinburg Analytical Instruments). The emission decays were detected using an Edinburgh FL900 spectrometer and processed using conventional software provided by Edinburgh Instruments. The sample is maintained in a sealed quartz tube under vacuum. Decays are always recorded in degassed environment. Measurements were excited at $\lambda_{\text {exc }}=310 \mathrm{~nm}$, collecting the emission signal in the maximum of the emission band (410-420 nm). For a lifetime analysis we used multiexponential functions and the response function was convoluted with the instrumental response as previously described. ${ }^{34}$

\section{Computational details}

The geometry of minimum energy was determined for every oligomer using the molecular mechanics method named Sybyl, ${ }^{35}$ implemented in the molecular package Spartan 5.0. ${ }^{36}$ Using this optimized geometry, we calculated the energy levels, the atomic charges and the dipole moments using the semi-empirical method PM3. ${ }^{37}$ The theoretical spectra and the oscillator strength of the electronic transitions were obtained with the semi-empirical method INDO as implemented in the molecular package Cerius $2{ }^{35-37}$ Theoretical absorption spectra were obtained by a configuration interaction (CI) calculation, taking into account the ground state and ten excited states.

\section{Results and Discussion}

Electronic absorption spectra of the PHF in diluted solutions (concentration $=1.2 \times 10^{-5} \mathrm{~mol} \mathrm{~L}^{-1}$ ) are shown in Figure 1. The absorption band is broader and without vibronic structure. In general, the broad UV absorption bands of polyfluorenes can be attributed to the electronic transition located in the central group with larger disordered conformational distribution attributed to the $\alpha$-backbone conformations. ${ }^{12-15,38}$ No absorption band from the $\beta$-ordered phase has been observed for this polymer in such diluted solutions. In general this phase is spectroscopically observed for polyfluorenes by a sharper excitation/absorption peak at the red edge of the more intense absorption from fluorenyl groups.

A higher energy band is observed for more polar solvents $\left(\lambda_{\max }=356 \mathrm{~nm}\right.$ for chloroform $)$ and lower energy bands appears for less polar solvents: $\lambda_{\max }=365 \mathrm{~nm}$ for toluene

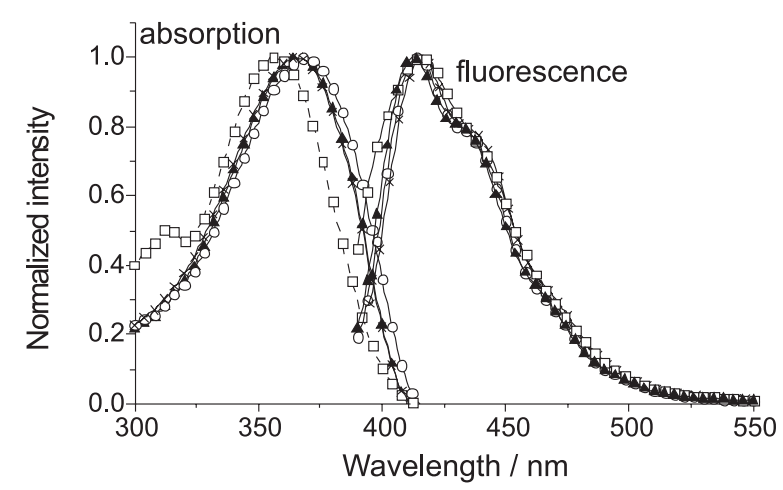

Figure 1. Electronic absorption and fluorescence spectra of poly(2,7-9,9'dihexylfluorene-dyil) in solutions of: toluene (- $\left.\boldsymbol{\Delta}^{-}\right)$, THF (-O-), chloroform $(-\square-)$ and ethyl acetate $(-\times-)$. Concentration $=1.2 \times 10^{-5} \mathrm{~mol} \mathrm{~L}^{-1}$.

and ethyl acetate and $\lambda_{\text {max }}=369 \mathrm{~nm}$ for THF (Figure 1). This spectral blue-shift observed for chloroform can be associated to a larger stability of the electronic ground state compared with the electronic excited state which is a usual behavior in polar solvents when the polarity of the excited state is smaller than that of the ground state. ${ }^{33}$ Also, although chloroform is a good solvent for polyfluorenes, its higher polarity leads to some angular tension effects that contribute to a smaller effective conjugation length, as a result of salvation effect. This effect is evidenced by the absorption band at $315 \mathrm{~nm}$ and its blue-shift, as well.

Theoretically optimized geometries were also determined for all oligomers using the Sybyl molecular mechanical methodology followed by calculations using PM3 method to calculate orbital energies. This approach gives a qualitative representation of the geometry and energy levels without expending longer computational time. ${ }^{29}$ The molecular orbital schemes for both HOMO and LUMO is illustrated in Figure 2 for the fluorene with $\mathrm{n}=1$ and for one oligomer with $n=8$. These representations indicate a larger electronic density over the central atoms of the fluorene moieties and that the structure of these central rings is relatively planar. This planar geometry is maintained in both the electronic ground state and electronic excited state independently of the oligomer size. The contribution of the charge density over the central group decreases for longer oligomers. Although the geometry of the central fluorenyl units is planar, the geometry of the backbone was distorted from the fluorene plane (see Figure $2 b$ as an example).

Using the optimized geometry and the atomic charge of every one of these oligomers, we estimated the dipole moment using PM3 method (Table 1). The dipole moment for this coil arrangement of the polymer backbone oscillates in a magnitude going from an initially high value for $n=1$ $(0.29 \mathrm{D})$, that decreases to $0.13 \mathrm{D}$ for $\mathrm{n}=2$, undergoing an increase to $0.37-0.39$ for $n=3-4$, to 0.59 for $n=5$, decreases drastically to 0.14 for $n=6$, when a turn is 

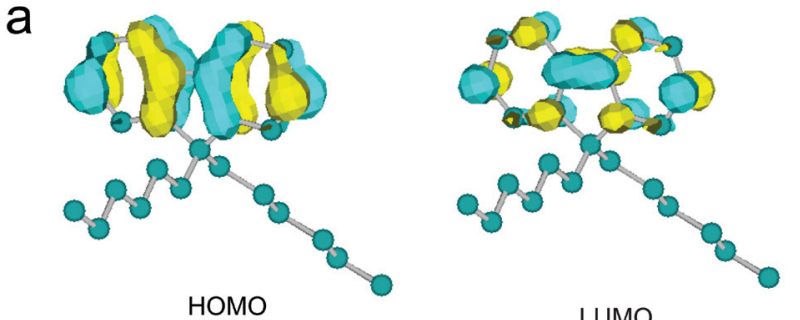

LUMO

b
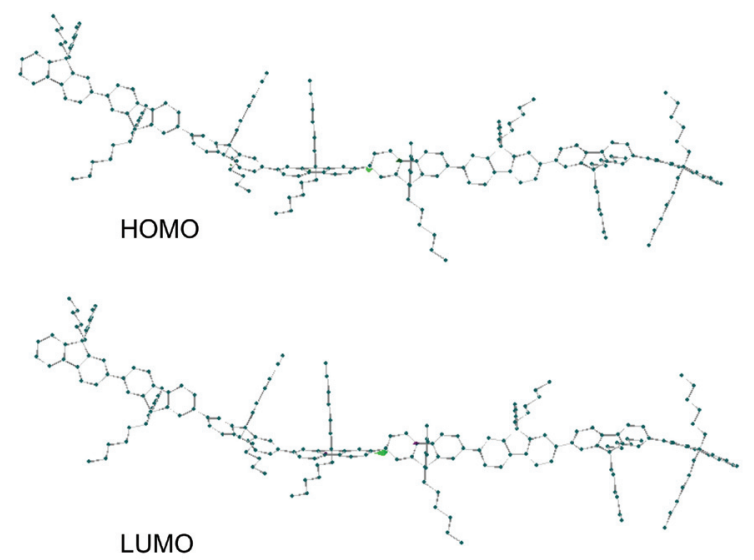

Figure 2. Geometry representation of the HOMO and LUMO for fluorene with a) $n=1$ and b) one oligomer with $n=8$ using the PM3 method.

completed and then goes back to 0.28 for $n=7$, following the same tendency for $n=8-11$. These data showed the dependence of dipole moment with chain length or the number of mers and is a consequence of the helical structure of the polymer chain. The proposal helical structure obtained by the theoretical data is in agreement with the $\mathrm{X}$-ray diffraction data ${ }^{13}$ and is also obtained by quantum mechanical calculations reported for other polyfluorene derivatives. ${ }^{13,38,39}$ According with these reported results, the main chain has a torsional angle of around $36^{\circ}$ and the coil is replicated for $\mathrm{n}=8 .{ }^{37}$

The calculated energies of the HOMO and LUMO are also presented in Table 1 . The energy gap becomes constant for oligomers with $\mathrm{n} \geq 6$, changing from $298 \mathrm{~nm}$ for $\mathrm{n}=1$ to $351.7 \mathrm{~nm}$ for $\mathrm{n}=6$, which were considered the critical size for the conjugative effects of one repeating unit over the electronic transition located in a specific fluorenyl moiety.

Spectral behavior of these oligomers was also theoretically simulated using the calculated oscillator strength (Table 1), the peak position of the band and a gaussian function for the band shape (Figure 3). The band position changes from the higher energy and lower intensity for short oligomers to lower energy and higher intensity for larger molecules and for oligomers with $n \geq 6$ the peak position is constant. When compared with the experimental data, the theoretical band absorption at $351.7 \mathrm{~nm}$ for the oligomer is in good agreement with the band centered at $365 \mathrm{~nm}$ observed for the polymer in less polar solvents, considering the all approximations of theoretical methodology used. Because of this three dimensional structure, $\pi-\pi$ stacking structure of this polymer is inhibited and we do not expect emission from aggregates as observed for other conjugated aromatic polymers.

The PHF fluorescence spectra were also obtained for the same dilute solutions whose absorption spectra were also depicted in Figure 1. These emission spectra have a vibronic structure partially resolved as usually observed for fluorene-based polymers. ${ }^{2-8,10-17}$ Furthermore, the emission profile is similar for all solvents with small spectral shifts $\left(\lambda_{\max }=415 \mathrm{~nm}\right.$ for chloroform, $\lambda_{\max }=412 \mathrm{~nm}$ for toluene, $\lambda_{\text {max }}=414 \mathrm{~nm}$ for THF and $\lambda_{\text {max }}=416 \mathrm{~nm}$ for ethyl acetate).

Table 1. Energies of the HOMOs and LUMOs and dipole moments for oligomers with $n=1$ to $n=8$. Energy differences in Hartree, $\mathrm{eV}$ and $\mathrm{nm}$

\begin{tabular}{|c|c|c|c|c|c|c|c|c|}
\hline & \multicolumn{8}{|c|}{ Oligomer } \\
\hline & $\mathrm{n}=1$ & $\mathrm{n}=2$ & $\mathrm{n}=3$ & $\mathrm{n}=4$ & $\mathrm{n}=5$ & $\mathrm{n}=6$ & $\mathrm{n}=7$ & $\mathrm{n}=8$ \\
\hline $\mathrm{H}-2$ & -0.356 & -0.351 & -0.335 & -0.323 & -0.316 & -0.311 & -0.308 & -0.306 \\
\hline $\mathrm{H}-1$ & -0.351 & -0.335 & -0.317 & -0.310 & -0.306 & -0.303 & -0.302 & -0.301 \\
\hline HOMO & -0.321 & -0.312 & -0.302 & -0.300 & -0.299 & -0.299 & -0.298 & -0.298 \\
\hline LUMO & -0.016 & -0.025 & -0.035 & -0.037 & -0.038 & -0.038 & -0.039 & -0.039 \\
\hline $\mathrm{L}+1$ & 0.012 & -0.005 & -0.021 & -0.028 & -0.032 & -0.034 & -0.035 & -0.036 \\
\hline $\mathrm{L}+2$ & 0.013 & 0.010 & -0.007 & -0.016 & -0.023 & -0.027 & -0.030 & -0.032 \\
\hline $\begin{array}{l}\text { LUMO-HOMO / Hartree } \\
\qquad \begin{array}{l}\mathrm{eV} \\
\mathrm{nm}\end{array}\end{array}$ & $\begin{array}{c}0.305 \\
8.30 \\
298\end{array}$ & $\begin{array}{c}0.287 \\
7.81 \\
317.5\end{array}$ & $\begin{array}{c}0.267 \\
7.27 \\
341.1\end{array}$ & $\begin{array}{c}0.263 \\
7.16 \\
346.3\end{array}$ & $\begin{array}{c}0.261 \\
7.10 \\
349.3\end{array}$ & $\begin{array}{c}0.261 \\
7.10 \\
349.3\end{array}$ & $\begin{array}{c}0.259 \\
7.05 \\
351.7\end{array}$ & $\begin{array}{c}0.259 \\
7.05 \\
351.7\end{array}$ \\
\hline Oscillator strength & 0.307 & 1.347 & 2.458 & 3.232 & 3.963 & 4.985 & & \\
\hline$\mu$ / Debye & 0.29 & 0.13 & 0.37 & 0.39 & 0.59 & 0.14 & 0.28 & 0.4 \\
\hline
\end{tabular}

For other oligomers: $\mu$ (Debye) $=0.48(n=9), 0.45(n=10), 0.34(n=11)$. 


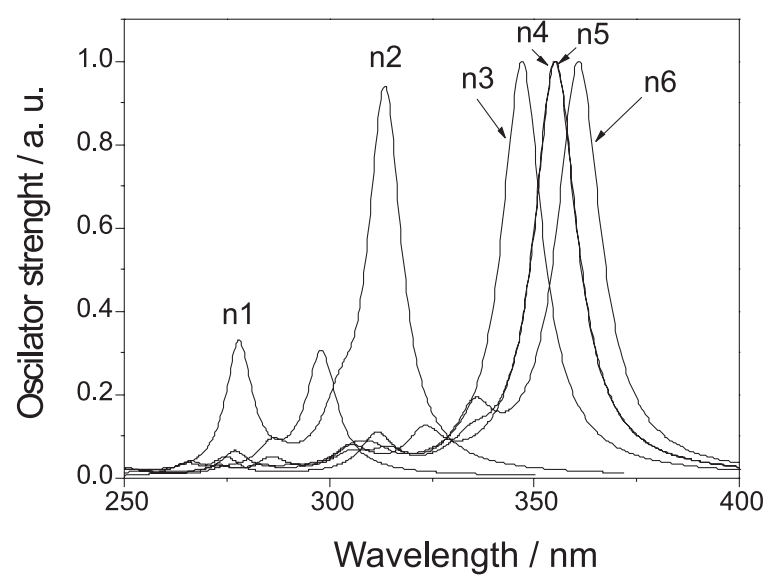

Figure 3. Simulated electronic absorption fluorene compound with $n=1$ and its oligomers with $2 \geq \mathrm{n} \geq 6$ obtained using the ZINDO semi-empirical quantum mechanical method.

The absence of the mirror image emission absorption spectra and the large observed Stokes's shift, in the range of 3000-4000 $\mathrm{cm}^{-1}$, indicate that conformational relaxations in the same time scale of the emission is a relevant process for this polymer as also observed for other polyfluorenes. ${ }^{20}$ Considering both the large Stokes shift and the different band profiles of the excitation and emission spectra, we may conclude that the emitting and absorption centers are not necessarily the same.

The fluorescence quantum yields $\left(\phi_{\mathrm{F}}\right)$ for the polymer were determined for these solutions using quinine sulfate as a standard (Table 2). Values are relative high for all solvents, ranging from 0.52 for THF, 0.49 for toluene and chloroform and 0.36 for ethyl acetate solutions, confirming that polyfluorene derivatives are strong fluorescent materials.

Steady-state excitation and fluorescence spectra of PHF thin films (Figure 4) are specular images, centered respectively at $366 \mathrm{~nm}$ and $420 \mathrm{~nm}$. This behavior suggests that while conformational relaxation is important for solutions, it is less relevant for the solid state. We observe that while the absorption is similar in both solution and solid state, the emission in solid state is red-shifted compared to that in dilute solutions. The spectral red-shift in solid state may be attributed to several effects. ${ }^{33}$ One possibility is the inner-filter effect in condensed system that is relevant for thicker films or films were the molar absorptivity is very high. ${ }^{3,31} \mathrm{We}$ are assuming that this effect is not playing a major role in the present samples whose thickness is around $70 \mathrm{~nm}$. The other possibility is the aggregation processes of the polymer in solid state, which may be responsible by the presence of excimer emission, emission from ground state dimmers or red-edge emission band..$^{2-4,13-15,20,38}$ Here we are not observing excimer emission since the excitation and the absorption profiles are very similar, no red-edge emission band has been detected and consequently the presence of dimmers can be excluded. The coil conformation is probably inhibiting the spatial coupling between fluorenyl units and imposing restraints to the dimmer or excimer formations. Some other possibility arises from the solvation layer around a specific chain that is involved by other chains. As observed for solvents, PHF emission is shifted for higher energy in more polar solvent. Assuming this dipolar interaction, the solvation layer around every chain behaves as a less polar cavity compared with solvents. Finally, the other effect that plays important role in the spectral shift is the energy transfer process. ${ }^{33}$ This process can be verified by fluorescence lifetime measurements.

The PHF fluorescence decays in those four solvents, toluene, THF, chloroform and ethyl acetate, were monoexponential with lifetimes of $0.65,0.74,0.64$ and $0.70 \mathrm{~ns}$, respectively. Fluorescence decays in the range of 0.2-0.5 ns have been observed for some other polyfluorenes. ${ }^{20}$ The fluorescence decay of PHF thin films

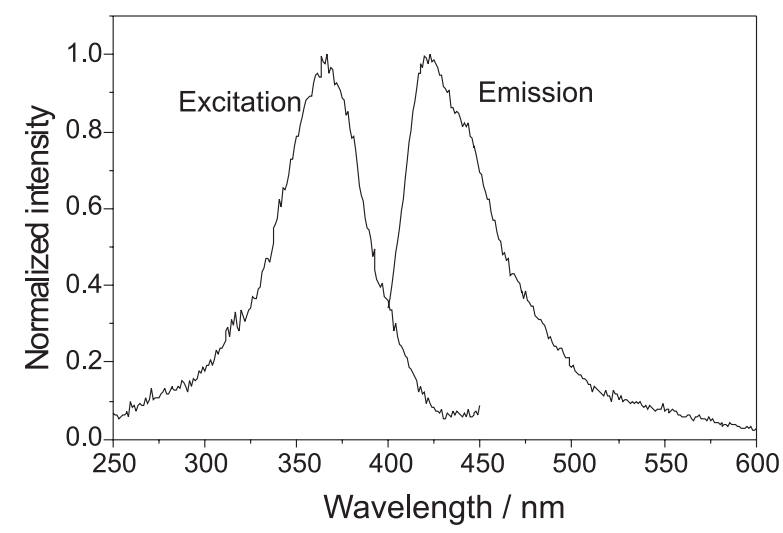

Figure 4. Excitation $\left(\lambda_{\mathrm{em}}=420 \mathrm{~nm}\right)$ and emission $\left(\lambda_{\mathrm{exc}}=366 \mathrm{~nm}\right)$ spectra of poly(2,7-9,9'-dihexylfluorene-dyil) thin film.

Table 2. Some photophysical parameters for poly(2,7-9,9'-dihexylfluorene-dyil) in four solvents and solid state

\begin{tabular}{lccccc}
\hline & toluene & THF & chloroform & ethyl acetate & film \\
\hline$\lambda_{\text {abs }} / \mathrm{nm}$ & 365 & 369 & 356 & 365 & 366 \\
$\lambda_{\mathrm{FL}} / \mathrm{nm}$ & 414 & 416 & 416 & 412 & 420 \\
$\phi_{\mathrm{F}}{ }^{\mathrm{a}}$ & 0.49 & 0.52 & 0.49 & 0.36 & ---- \\
$\tau_{\mathrm{F}} / \mathrm{ns}$ & 0.65 & 0.74 & 0.64 & 0.70 & 0.54 \\
\hline
\end{tabular}

${ }^{\mathrm{a}}$ with respect to aqueous solution of quinine sulfate $0.1 \mathrm{~mol} \mathrm{~L}^{-1}$ in $\mathrm{H}_{2} \mathrm{SO}_{4}$. Solution concentration: $=1.2 \times 10^{-5} \mathrm{~mol} \mathrm{~L}^{-1}$. 
is also monoexponential, with a lifetime of $0.54 \mathrm{~ns}$, which is faster than that in dilute solutions. Faster decays can be observed for systems where energy transfer processes are playing some role, ${ }^{33}$ which suggests that it is one of the reasons for the spectral red-shift. This faster decay compared with the solution indicates that some energy transfer processes are occurring in the solid state. This photophysical behavior also observed for other fluorenebased polymers indicates that the excited state lumophores involved with the radiative decay is the fluorenyl moiety; that this isolate lumophore is disturbed by the presence of up to 7 other mers (see the persistent length in the absorption spectra); that solvation layer induces spectral shift and energy transfer among fluorenyl moieties is possible, probably by inter-chain dipolar interaction. It is also noteworthy that the fluorescence emission in solid state is very similar to the electroluminescence emission reported for this polymer, indicating that the same electronically excited state is responsible by both emissions. ${ }^{32}$

\section{Conclusions}

We determined the PHF photophysical properties in both dilute solutions and solid state. We observed that the emission spectra in solid state and dilute solution are similar, indicating that the fluorene moiety is the emissive group. Lifetime measurement confirms this assignment. The electroluminescence spectrum reported ${ }^{32}$ for this polymer displayed a spectrum similar to that of photoluminescence, showing that the exciton recombination produces an isolated fluorenyl group in the excited state which emits in the bluerange of the visible spectrum. Theoretical calculations showed that the persistent length of the fluorenyl units involved with the emission becomes invariant between 6-7 mers. Theoretical calculations also showed that the polymer backbone is arranged in a coil conformation around the chain axis and that the turns at each 8 repeating units. This three dimensional conformation probably avoids the aggregation of the polymer chain in solid state, reducing the probability of excimer or aggregation emissions.

\section{Acknowledgments}

The authors thank FAPESP, CNPq, FAEPEX/ UNICAMP, CAPES and IMMP/PADCT/MCT for financial supports and fellowships. We also thank Prof. Carol Collins for useful discussions.

\section{References}

1. Akcelrud, L.; Prog. Polym. Sci. 2003, 28, 875.
2. Machado, A. M.; Neto, J. D. D.; Cossiello, R. F.; Atvars, T. D. Z.; Ding, L.; Karasz, F. E.; Akcelrud, L.; Polymer 2005, 46, 2452.

3. Machado, A. M.; Munaro, M.; Martins, T. D.; Davila, L. Y. A.; Giro, R.; Caldas, M. J.; Atvars, T. D. Z.; Akcelrud, L. C.; Macromolecules 2006, 39, 3398.

4. Gruber, J.; Li, R. W. C.; Aguiar, L. H. J. M. C.; Garcia, T. L.; Oliveira, H. P. M.; Atvars, T. D. Z.; Nogueira, A. F.; Synth. Met. 2006, 156, 104.

5. Yang, S. H..; Lee, C. F. J.; Optoelectr. Adv. Mat. 2007, 9 , 2078.

6. Chang L. H.; Lee, Y. D.; Chen, C. T.; Macromolecules 2006, 39, 3262.

7. Zhang H. A.; Li Y.; Jinag Q.; Xie M. G.; Peng J. B.; Cao Y.; J. Mater. Sci. 2007, 42, 4476.

8. Gu, Z.; Bao, Y.-J.; Zhang, Y.; Wang, M.; Shen, Q.-D.; Macromolecules 2006, 39, 3125.

9. Krasovitskii, R. M.; Bolotin, B. M.; Organic Luminescent Materials, translated by Vopian, V. G.; VCH: Weinheim, 1988.

10. Cornil, J.; Gueli, I.; Dkhissi, A.; Sancho-Garcia, J. C.; Hennebicq, E.; Calbert, J. C.; Lemaur, V.; Beljonne, J.; Brédas, J. L.; J. Chem. Phys. 2003, 118, 6615.

11. Geng, Y.; Culligan, S. W.; Trajkovska, A.; Wallace, J. U.; Chen, S. H.; Chem. Mater. 2003, 15, 542; Korovyanko, O. J.; Vardeny, Z. V.; Chem. Phys. Lett. 2002, 356, 361; Banach, M. J.; Friend, R. H.; Sirringhaus, H.; Macromolecules 2003, 36, 2838; Grell, M.; Bradley, D. D. C.; Ungar, G.; Hill, J.; Whitehead, K. S.; Macromolecules 1999, 32, 5810; Banach, M. J.; Friend, R. H.; Sirringhaus, H.; Macromolecules 2004, 37, 6079; Knaapila, M.; Stepanyan, R.; Torkkeli, M.; Lyons, B. P.; Ikonen, T. P.; Almásy, L.; Foreman, J. P.; Serimaa, R.; Güntner, R.; Scherf, U.; Monkman, A. P.; Phys. Rev. E 2005, 71, 041802.

12. Dias, F. B; Morgado J.; Maçanita, A. L.; Costa, P. C.; Burrows, H. D.; Monkman, A. P.; Macromolecules 2006, 39, 5854.

13. Grell, M.; Bradley, D. D. C.; Ungar, G.; Hill, J.; Whitehead, K. S.; Macromolecules 1999, 32, 5810.

14. Chen, S. H.; Chou, H. L.; Su, A. C.; Chen, S. A.; Macromolecules 2004, 37, 6833.

15. Winokur, M. J.; Slinker, J.; Huber, D. L.; Phys. Rev. B 2003, 67, 184106.

16. Amrutha, S. R.; Jayakannan, M.; J. Phys. Chem. B 2006, 110, 4083.

17. Jeng, U.; Hsu, C. H.; Sheu, H. S.; Lee, H. Y.; Inigo, A. R.; Chiu, H. C.; Fann, W. S.; Chen, S. H.; Su, A. C.; Lin, T. L.; Peng, K. Y.; Chen, S. A.; Macromolecules 2005, 38, 6566.

18. Schwartz, B. J.; Ann. Rev. Phys. Chem. 2003, 54, 141.

19. Cadby, A. J.; Lane, P. A.; Mellor, H.; Martin, S. J.; Grell, M.; Giebeler, C.; Bradley, D. D. C.; Wohlgenannt, M.; An, C.; Vardeny, Z. V.; Phys. Rev. B 2000, 62, 15604. 
20. Vaughan, H. L.; Dias, F. M. B.; Monkman, A. P.; J. Chem. Phys. 2005, 122, 014902.

21. Fytas, G.; Nothofer, H. G.; Scherf, U.; Vlassopoulos, D.; Meier, G.; Macromolecules 2002, 35, 481.

22. Cossiello, R. F.; Akcelrud, L.; Atvars, T. D. Z.; J. Braz. Chem. Soc. 2005, 16, 74.

23. Deichmann, V. A. F.; Lisboa-Filho, P. N.; Martins, T. D.; Atvars, T. D. Z.; Akcelrud, L.; J. Lumin. 2007, 124, 343.

24. Nguyen, T.-Q.; Schwartz, B. J.; J. Phys. Chem. B 2001, 105, 5153.

25. Dewar, M. J. S.; Zoebisch, E. G.; Healy, E. F.; Stewart, J. J. P.; J. Am. Chem. Soc. 1985, 107, 3902; Neto, J. D.M.; Zerner, M. C.; Int. J. Quantum Chem. 2001, 81, 187.

26. Oliveira, M. A.; Almeida, W. B.; Santos, H. F.; J. Braz. Chem. Soc. 2004, 15, 832.

27. Murrel, N. J.; Harget, A. J.; Semi-Empirical Self-Consistent Molecular Orbital Theory of Molecules, Wiley: London, 1972.

28. Pearl, G. M.; Zener, M. C.; Broo, A.; McKelvey, J.; Cerius2 User Guide, Molecular Simulations Inc.: San Diego; J. Comput. Chem. 1998, 19, 781.

29. Del Nero, J.; Silva, J. A. P.; Silva, S. B. C.; Galembeck, A.; Synth. Met. 2003, 135-136, 157.

30. Barton, A. F. M.; Handbook of Solubility Parameters and other Cohesion Parameters; CRC Press: Boca Raton, Florida, 1983, p. 232 .
31. Cossiello, R. F.; Susman, M. D.; Aramendia P. F.; Atvars, T. D. Z., unpublished results.

32. Assaka, A. M.; Rodrigues, P. C.; de Oliveira, A. R. M.; Ding, L.; Hu, B.; Karasz, F. E.; Akcelrud, L.; Polymer 2004, 25, 7071.

33. Birks, J. B.; Photophysics of Aromatic Molecules, John Wiley \& Sons Ltd.: New York, 1970.

34. De Andrade, M. L; Atvars, T. D. Z.; J. Phys. Chem. B 2004, 108, 3975.

35. Clark, M.; Cramer III, R. D.; Van Opdenbosch, N.; J. Comput. Chem. 1989, 10, 982.

36. Spartan 5.0: Program for Molecular Mechanics and Quantum Chemical Calculations; University of California, USA, 1997.

37. Stewart, J. J. P.; J. Comput.-Aided Mol. Des. 1990, 4, 1.

38. Hennecke, M.; Damerau, T.; Müllen, K.; Macromolecules 1993, 26, 3411 .

39. Lieser, G.; Oda, M.; Miteva, T.; Meisel, A.; Nothofer, H. G.; Scherf, U.; Neher, D.; Macromolecules 2000, 33, 4490.

Received: April 30, 2008

Web Release Date: November 28, 2008

FAPESP helped in meeting the publication costs of this article. 